\title{
Perfil de ácidos graxos, composição centesimal e valor calórico de moluscos crus e cozidos com leite de coco da cidade de Maceió-Al
}

\author{
Giselda Macena Lira ${ }^{1 * 4}$, Jorge Mancini Filho² ${ }^{2}$ Lea Sílvia Sant'ana ${ }^{3}$, Rosângela Pavan Torres², \\ Alane Cabral de Oliveira ${ }^{4}$, Cristhiane Maria Bazílio de Omena ${ }^{4}$, Maria de Lourdes da Silva $\mathrm{Neta}^{4}$
}

${ }^{1 * 4}, 4$ Departamento de Nutrição, CSAU, Universidade Federal de Alagoas, ${ }^{2}$ Departamento de Alimentos e Nutrição Experimental, Faculdade de Ciências Farmacêuticas, Universidade de São Paulo,

${ }^{3}$ Faculdade de Ciências Agronômicas, Departamento de Tecnologia de Produtos de Origem Animal, Universidade Estadual de São Paulo, Botucatu

* Correspondência:

G. .M. Lira

Departamento de Nutrição-CSAU -

Universidade Federal de Alagoas

BR 101, Km 14 - CEP 57.072-900 -

Maceió - AL

E-mail:gmlira@ofm.com.br
Este estudo teve como objetivo caracterizar o perfil de ácidos graxos, a composição centesimal e o valor calórico de moluscos crus e cozidos da cidade de Maceió. Analisaram-se três espécies: sururu (Mytella falcata), maçunim (Anomalocardia brasiliana) e unha de velho (Tagelus plebeus), nas formas cruas e cozidas (ao molho de coco). Os moluscos in natura apresentaram elevados teores de umidade e proteinas. Os maiores teores de lipídeos e cinzas foram encontrados no sururu e maçunim, respectivamente. O sururu apresentou maior valor calórico. Em base seca, detectou-se que a cocção provocou redução significativa nos teores de proteinas e aumento significativo nos teores de lipídeos e cinzas em todos os moluscos. O maior valor calórico foi detectado em unha de velho cozida. No perfil de ácidos graxos de todas as amostras cruas, os ácidos graxos poliinsaturados predominantes foram o docosaexaenóico e eicosapentaenóico. Também, foram encontrados os ácidos linoléico, linolênico e araquidônico. Após o cozimento, os teores dos ácidos graxos saturados láurico e mirístico aumentaram significativamente e o esteárico apresentou redução significativa em relação aos valores "in natura" em todas as espécies. O ácido linoléico sofreu redução significativa em unha de velho e maçunim. Os poliinsaturados linolênico, araquidônico, eicosapentanóico e docosaexaenóico apresentaram redução em todos os moluscos.
Unitermos

- Ácidos graxos Ômega-3

- Ácidos graxos Ômega-6

- Composição centesimal Moluscos

- Cocção com leite de côco

\section{INTRODUÇÃO}

A composição em ácidos graxos dos alimentos é de grande importância, principalmente os poliinsaturados das famílias ômega-3 e ômega-6, aos quais se atribuem nume- rosos benefícios ao organismo humano. A família ômega 3 (PUFA w-3) compreende o ácido graxo essencial alfalinolênico (C18:3, w-3), do qual, por alongamento e dessaturação, são gerados os ácidos eicosapentaenóico (EPA - C20:5 w-3) e docosaexaenóico (DHA - (C22:6 w- 
3) (Belda, Pourchet-Campos, 1991). A família ômega-6 compreende o ácido graxo essencial linoléico, que pode originar o ácido araquidônico.

Na manutenção da higidez da pele os ácidos graxos ômega-3, como os ômega-6, são importantes, integrando o stratus corneum através das ceramidas, evitando a perda de água transepidérmica, garantindo, assim, sua elasticidade e integridade. Evidências falam em favor de que os ácidos graxos ômega-3 e ômega- 6 sejam protetores contra o envelhecimento. São essenciais às membranas, ao bom funcionamento da vista, através da retina, ao desenvolvimento do cérebro e do sistema nervoso e dos fosfolípídeos existentes no organismo, entre outros. Para controle de fatores de risco das moléstias cardíacas e vasculares, destaca-se o ácido graxo ômega-3, desde que em proporções adequadas ( Belda, Pourchet-Campos, 1991).

Os ácidos graxos ômega-3 e ômega- 6 apresentam efeitos hipocolesterolêmicos e reduzem os níveis de LDL, através de modificação na composição das membranas celulares e das lipoproteínas, além de induzir o aumento das excreções biliar e fecal do colesterol, reduzindo a síntese do VLDL no fígado (British Nutrition Foundations, 1994). São os precursores de um conjunto de substâncias com atividades fisiológicas e farmacológicas denominadas eicosanóides, que abrangem as tromboxanas, prostaglandinas (que possuem efeitos hipotensores), prostaciclinas (inibe a agregação plaquetária e aumenta o HDL) e leucotrienos. O equilíbrio entre a produção de prostaglandinas e tromboxanas inibe o aparecimento de doenças cardiovasculares (Turatti, Gomes, Athié, 2002).

Epidemiologicamente, os ácidos graxos poliinsaturados ômega-3 mostram efeito benéfico na prevenção de vários tipos de câncer (Curi et al., 2002). Os ômega6 exercem importante papel fisiológico como potentes mediadores da inflamação e efeito benéfico sobre o sistema imune (Pompéia, Procópio, Curi, 1999).

Devido à disponibilidade dos ácidos graxos ômega3 e ômega-6 depender do fornecimento alimentar, é importante conhecer, dentre os alimentos, aqueles que podem ser fonte, mais ou menos valiosa, desses ácidos graxos essenciais.

Os moluscos bivalves são amplamente consumidos em Maceió. Diversos estudos realizados no Complexo Estuarino das lagoas Mundaú/Manguaba, o mais importante de Alagoas, pois em torno dele encontram-se cinco cidades e dois distritos, revelaram a existência de várias espécies de moluscos, sendo que, de maior importância comercial, se destacam o sururu (Mytella falcata), o maçunin (Anomalocardia brasiliana) e a unha de velho (Tagelus plebeus) (Silva, Pereira-Barros, 1987). A tem- peratura da água do Complexo Estuarino varia entre a máxima de $31{ }^{\circ} \mathrm{C}$ e a mínima de $25^{\circ} \mathrm{C}$. Esta pequena oscilação anual condiciona a uniformidade térmica para o desenvolvimento dos processos biológicos (Pereira Barros, 1983 Apud Calado, Souza, 2003). Ao contrário do comportamento uniforme da temperatura, a salinidade na região é um parâmetro de extrema variabilidade (Macedo et al., 1987 Apud Calado, Souza, 2003). Salinidade em torno de 9,5 mg.kg-1 representa o nível ótimo para o desenvolvimento destes moluscos (Asbury, 1979).

No entanto, embora ligados à própria história da cultura alagoana e enraizados nos hábitos alimentares da região, inexistem dados na literatura sobre o seu perfil de ácidos graxos e composição centesimal. Embora haja grande interesse médico e nutricional sobre os ácidos graxos ômega-3 e ômega- 6 , poucas pesquisas vêm sendo realizadas visando detectar as possíveis alterações que estes podem sofrer quando o alimento é processado.

O estudo detalhado da composição destes moluscos nas formas cruas e cozida, através de técnicas analíticas disponíveis, contribuirá com os profissionais da área de saúde para uma adequada orientação dietética, bem como na obtenção de dados que possam ser utilizados em tabelas de composição centesimal e de ácidos graxos de sua fração lipídica. A obtenção de dados referentes à composição de alimentos brasileiros tem sido estimulada com o objetivo de reunir informações atualizadas, confiáveis e adequadas à realidade nacional (Lajolo, 1995).

Este estudo teve como objetivo determinar o perfil de ácidos graxos, a composição centesimal e o valor calórico de moluscos crus e cozidos da cidade de Maceió-AL.

\section{MATERIAL E MÉTODOS}

\section{Material}

Analisaram-se 13 amostras cruas e 13 cozidas da parte comestível dos moluscos: sururu (Mytella falcata) e maçunim (Anomalocardia brasiliana) e 7 amostras do molusco unha de velho (Tagelus plebeus). Todas as amostras procederam da Lagoa Mundaú (Maceió-AL) e foram adquiridas em lotes, pesando cerca de $300 \mathrm{~g}$, no período de setembro de 2002 a maio de 2003. Em seguida, foram conduzidas ao Laboratório de Bromatologia do Departamento de Nutrição da Universidade Federal de Alagoas, onde as análises foram realizadas.

\section{Preparo das amostras}

Cada lote foi dividido em 2 porções de $150 \mathrm{~g}$. As porções cruas constituíram o grupo I e os produtos após cocção na forma usual da região, com leite de coco, sal e 
temperos (pimentão, tomate, coentro, cebola, alho e limão) corresponderam ao grupo II. Estes apresentaram tempos de cozimento distintos para cada espécie, considerandose as suas texturas características: sururu -20 minutos; maçunim - 15 minutos, unha de velho -17 minutos. Os tempos de cozimento foram computados a partir do momento do início da fervura e a temperatura para todas as espécies correspondeu a $95^{\circ} \mathrm{C}$. Após o cozimento, o meio de cocção utilizado (leite de coco) foi totalmente absorvido pelas amostras. Em seguida, as amostras foram trituradas em um processador de carne até a formação de massa homogênea.

\section{Métodos}

Em amostras dos grupos I e II, após homogeneização, realizaram-se as seguintes determinações em triplicata:

\section{Composição centesimal}

- Umidade - determinada pela perda de peso em estufa regulada a $105^{\circ} \mathrm{C}$ (AOAC, 1990).

- Cinzas - obtidas por incineração de uma quantidade conhecida da amostra, em mufla a $550^{\circ} \mathrm{C}$, até obtenção de peso constante (AOAC, 1990).

- Proteínas - dosada pelo método Kjedahl, que consiste na determinação do nitrogênio total. Para converter o resultado em proteína bruta foi utilizado o fator 6,25 (AOAC, 1990).

- Lipídeos Totais - extraídos a frio pelo método de Folch et al. (1957), utilizando 2 extrações com clorofórmio:metanol (2:1), lavagem do resíduo (clorofórmio:metanol - 2:1), adição de $\mathrm{KCl} \mathrm{0,88 \%} \mathrm{em} \mathrm{H}_{2} \mathrm{O}$, separação das fases, adição de metanol: $\mathrm{H}_{2} \mathrm{O}(1: 1)$, evaporação de clorofórmio em rota-evaporador, fração lipídica ressuspendida em clorofórmio. Alíquotas foram tomadas para determinações gravimétricas.

- Carboidratos - quantificados por diferença.

Os resultados foram expressos em percentagem, em relação ao peso da amostra integral e seca.

O valor calórico total foi calculado a partir dos coeficientes calóricos correspondentes para proteínas, lipídeos e fração Nifext (como carboidratos), respectivamente 4, 9 e $4 \mathrm{kcal} / \mathrm{g}$.

\section{Perfil de ácidos graxos}

Os extratos lipídicos obtidos pelo Método de Folch foram esterificados segundo Hartman e Lago (1973), visando à determinação da composição em ácidos graxos por cromatografia em fase gasosa e encaminhados ao Laboratório de Lípides do Departamento de Alimentos e
Nutrição Experimental, Faculdade de Ciências Farmacêuticas, USP, São Paulo, onde foram injetados em cromatógrafo a gás. Para a identificação dos ácidos graxos foram utilizados padrões de ésteres metílicos de ácidos graxos puros, comparando-se o tempo de retenção dos ésteres metílicos das amostras e dos padrões. A quantificação dos ácidos graxos foi feita por normalização de área, expressando-se o resultado em percentual de cada ácido sobre o total de ácidos graxos. Condições de análise: Cromatógrafo a gás GC 17 A Shimadzu/ Class GC 10; Coluna cromatográfica de sílica fundida Carbowax $20 \mathrm{M}$ (polietilenoglicol) de 30 metros, $0,25 \mathrm{~mm}$ de diâmetro interno e espessura da fase estacionária de 0,25 microns;

Programação de temperatura da coluna: aquecimento a $1{ }^{\circ} \mathrm{C} / \mathrm{min}$. de $170{ }^{\circ} \mathrm{C}$ até $225^{\circ} \mathrm{C}$, permanecendo nesta temperatura por $10 \mathrm{~min}$; Temperatura do injetor: $250^{\circ} \mathrm{C}$; Temperatura de detector: $270{ }^{\circ} \mathrm{C}$; Gás de arraste: hélio ( $1 \mathrm{~mL} / \mathrm{min}$.); Razão de divisão da amostra no injetor $($ split $)=1: 50$.

\section{Análise Estatística}

Utilizou-se a Análise de Variância (ANOVA), com o auxílio do programa estatístico Epi-info, versão 2002, a um nível de significância de 0,05 e 0,01. Quando as variâncias não foram homogêneas, testado pelo Qui-quadrado de Bartlett's, utilizou-se o teste de Kruskal-Wallis no mesmo nível de significância, através do mesmo programa.

\section{RESULTADOS E DISCUSSÃO}

\section{Composição centesimal}

Os resultados da composição centesimal dos moluscos estudados encontram-se na Tabela I.

Devido à extinção periódica da espécie unha de velho, no período de novembro de 2002 até maio de 2003, analisaram-se apenas 7 amostras deste molusco. Os moluscos crus apresentaram elevados teores de umidade e proteínas. Os maiores teores de lipídeos foram encontrados no sururu $(3,84 \%)$, o qual apresentou maior valor calórico $(107,72)$. Quanto às cinzas, os maiores valores foram detectados no maçunim $(2,24 \%)$.

Os resultados obtidos em base seca, utilizada para eliminar a influência da umidade, demonstraram que a cocção provocou redução significativa $(p>0,05)$ nos teores de proteínas e aumento significativo $(p>0,05)$ nos teores de cinzas em todos os moluscos. O percentual de perdas protéicas devido ao cozimento correspondeu a $38 \%$ no sururu e maçunim e $35 \%$ em unha de velho. Durante o cozimento, as proteínas se desnaturam, em um processo em 
TABELA I - Composição centesimal ( $\mathrm{g} \%$ ) e calórica de moluscos crus e cozidos em leite de coco da cidade de MaceióAL, em base úmida e seca

\begin{tabular}{lllllll}
\hline Moluscos & Umidade & Proteínas & Lipídeos & Cinzas & F. Nifext & Calorias (Kcal) \\
\hline $\begin{array}{l}\text { Sururu cru } \\
\text { (B. úmida) }\end{array}$ & $76,68( \pm 1,25)$ & $17,26( \pm 1,76)$ & $3,84( \pm 1,07)$ & $1,80( \pm 0,47)$ & $1,03( \pm 0,95)$ & 107,72 \\
$\begin{array}{l}\text { Sururu cru } \\
\text { (B. seca) }\end{array}$ & - & $73,00^{\mathrm{a}}( \pm 6,23)$ & $15,75^{\mathrm{a}}( \pm 4,33)$ & $7,8^{\mathrm{a}}( \pm 2,39)$ & $4,78^{\mathrm{a}}( \pm 4,27)$ & - \\
$\begin{array}{l}\text { Sururu cozido } \\
\text { (B. úmida) }\end{array}$ & $73,14( \pm 2,78)$ & $11,98( \pm 2,00)$ & $7,09( \pm 1,39)$ & $3,11( \pm 0,39)$ & $4,67( \pm 2,03)$ & 130,49 \\
$\begin{array}{l}\text { Sururu cozido } \\
\text { (B. seca) }\end{array}$ & - & $45,09^{\mathrm{b}}( \pm 6,47)$ & $25,90^{\mathrm{b}}( \pm 4,33)$ & $11,0^{\mathrm{b}}( \pm 1,58)$ & $16,4^{\mathrm{b}}( \pm 7,62)$ & - \\
$\begin{array}{l}\text { Maçunim cru } \\
\text { (B. úmida) }\end{array}$ & $75,35( \pm 1,97)$ & $17,46( \pm 1,42)$ & $2,68( \pm 0,47)$ & $2,24( \pm 0,70)$ & $2,39( \pm 1,56)$ & 103,52 \\
$\begin{array}{l}\text { Maçunim cru } \\
\text { (B. seca) }\end{array}$ & - & $70,58^{\mathrm{a}}( \pm 6,80)$ & $10,40^{\mathrm{a}}( \pm 2,30)$ & $8,50^{\mathrm{a}}( \pm 2,74)$ & $9,18^{\mathrm{a}}( \pm 6,23)$ & - \\
$\begin{array}{l}\text { Maçunim cozido } \\
\text { (B. úmida) }\end{array}$ & $72,53( \pm 2,30)$ & $12,52( \pm 2,65)$ & $6,61( \pm 0,94)$ & $3,31( \pm 0,59)$ & $5,02( \pm 2,32)$ & 129,65 \\
$\begin{array}{l}\text { Maçunim cozido } \\
\text { (B. seca) }\end{array}$ & - & $43,70^{\mathrm{b}}( \pm 10,45)$ & $22,50^{\mathrm{b}}( \pm 2,88)$ & $11,67^{\mathrm{b}}( \pm 2,58)$ & $18,55^{\mathrm{b}}( \pm 9,52)$ & - \\
$\begin{array}{l}\text { U. V.* cru } \\
\text { (B. úmida) }\end{array}$ & $76,70( \pm 0,49)$ & $16,39( \pm 2,51)$ & $2,84( \pm 0,93)$ & $1,61( \pm 0,41)$ & $2,35( \pm 2,59)$ & 100,52 \\
$\begin{array}{l}\text { U. V.* cru } \\
\text { (B. seca) }\end{array}$ & - & $69,71^{\mathrm{a}}( \pm 10,59)$ & $13,67^{\mathrm{a}}( \pm 5,51)$ & $7,00^{\mathrm{a}}( \pm 1,82)$ & $8,80^{\mathrm{a}}( \pm 1,38)$ & - \\
$\begin{array}{l}\text { U. V.* cozida } \\
\text { (B. úmida) }\end{array}$ & $68,91( \pm 1,41)$ & $14,00( \pm 3,19)$ & $6,75( \pm 1,22)$ & $3,44( \pm 0,61)$ & $6,92( \pm 3,87)$ & 144,43 \\
$\begin{array}{l}\text { U. V.*ozida } \\
\text { (B. seca) }\end{array}$ & - & $45,00^{\mathrm{b}}( \pm 10,77)$ & $20,60^{\mathrm{a}}( \pm 4,72)$ & $10,60^{\mathrm{b}}( \pm 2,30)$ & $21,17^{\mathrm{a}}( \pm 3,85)$ & - \\
\hline
\end{tabular}

* Unha de Velho; Média de amostras analisadas em triplicata com desvio-padrão entre parêntesis; Médias com letras diferentes significam diferenças estatisticamente significativas $(p<0,05)$.

que as proteínas solúveis tornam-se insolúveis e perdem parte da umidade. Por isto, a carne crua contém mais água que a cozida. De certo modo, a perda de água é proporcional à duração do tratamento térmico. O suco que se perde arrasta alguns nutrientes solúveis em água (Price, Schweigert, 1994).

Em relação aos lipídeos, verificou-se aumento significativo ( $p>0,05)$ em sururu e maçunim. Os moluscos tiveram os seus teores lipídicos aumentados em torno de duas vezes, podendo-se considerar que houve absorção da gordura presente no leite de coco utilizado no cozimento. Moura e Tenuta-Filho (2002), estudando o efeito do processamento em camarão-rosa, verificaram que as amostras submetidas à fritura tiveram seus teores lipídicos significativamente aumentados em três vezes.

Os moluscos crus apresentaram valores de umidade inferiores aos encontrados para mexilhão por Pedrosa e Cozzolino (2001), na cidade de Natal-RN (81,58\%). Quanto aos lipídeos, dados de outras pesquisas apresentaram valo- res semelhantes, bem como níveis inferiores. Masson et al. (1990) encontraram 2,3\% de lipídeos para ostras (Ostrea chilensis). Bragagnolo e Rodriguez-Amaya (1997), encontraram teor médio de lipídeos de $1 \%$, variando de 0,8 a 1,1\% em camarão rosa (Penaeus brasiliensis) in natura. Moura e Tenuta Filho (2002) encontraram níveis de 1,13\% para camarão rosa (Penaeus brasiliensis e Penaeus paulensis) in natura. Pedrosa e Cozzolino (2001) encontraram concentrações de lipídeos de 1,10\% para mexilhão cru (Anomalocardia brasiliana).

Ao se comparar os percentuais de proteínas, com aqueles relatados por Pedrosa e Cozzolino (2001), observam-se teores inferiores aos do presente estudo: camarão $(10,62 \%)$, caranguejo $(13,30 \%)$, ostra $(14,19 \%)$, mexilhão $(12,67 \%)$, exceto para lagosta (21,38\%). Quanto à fração cinzas, os moluscos estudados também apresentaram valores mais elevados que os obtidos por Pedrosa e Cozzolino (2001): camarão (1,05\%), caranguejo $(0,71 \%)$, lagosta $(1,57 \%)$, ostra $(1,36 \%)$, mexilhão $(2,12 \%)$. 
Não será possível a comparação dos resultados obtidos com dados publicados na literatura, no que diz respeito às amostras cozidas, visto que não foram encontrados artigos disponíveis sobre a composição química de moluscos cozidos, utilizando leite de coco.

\section{ÁCIDOS GRAXOS}

O perfil de ácidos graxos encontrados nas espécies de moluscos estudadas é apresentado nas Tabelas II, III e IV. As análises estatísticas foram realizadas comparando-se os resultados dos moluscos da mesma espécie nas formas cruas e cozidas.

Os resultados obtidos nas amostras cruas de sururu indicaram predominância dos seguintes ácidos graxos: palmítico $(27,06 \%)$, palmitoléico (11,94\%), DHA - ômega 3 - (10,60\%), esteárico $(10,39 \%)$ e EPA - ômega 3 $(8,67 \%)$. No maçunim, observou-se predominância dos ácidos graxos palmítico $(22,45 \%)$, láurico $(9,41 \%)$, DHA - ômega 3 - $(8,80 \%)$ e esteárico $(7,94 \%)$. Foi detectada a presença do EPA $(6,76 \%)$. Em unha de velho foram identificadas as maiores porcentagens para os ácidos graxos palmítico $(26,75 \%)$, palmitoléico $(12,68 \%)$, oléico e isômeros $(10,02 \%)$ e DHA - ômega 3 - $(9,19 \%)$. O ácido EPA foi encontrado na proporção de $6,12 \%$.

Para todas as espécies cruas, encontraram-se os ácidos graxos poliinsaturados linoléico (ômega-6), linolênico (ômega-3) e araquidônico (ômega-6). O ácido araquidônico participa na formação da bainha de mielina das terminações nervosas e de sua recomposição nos casos de esclerose múltipla (Turatti et al., 2002).

Observou-se a predominância dos ácidos graxos saturados palmítico, esteárico e mirístico nos moluscos sururu e unha de velho. Em maçunim houve predominância de palmítico, láurico e esteárico. O sururu apresentou as maiores percentagens de poliinsaturados $(32,22 \%)$, de saturados $(52,88 \%)$, e os maiores valores de ômega-3 $(21,49 \%)$.

Em maçunim e unha de velho foram encontrados valores similares de poliinsaturados, de saturados e de ômega-3. Em unha de velho detectaram-se os maiores valores de monoinsaturados $(22,70 \%)$ e de ômega- 6 $(9,19 \%)$.

No maçunim foram detectados os menores teores de

TABELA II - Perfil de ácidos graxos de sururu cru e cozido em leite de coco da cidade de Maceió-AL

\begin{tabular}{lll}
\hline Ácidos Graxos & Sururu cru & Sururu cozido em leite de coco e temperos \\
\hline C12:0 (Láurico) & $6,06( \pm 2,89)^{\mathrm{a}}$ & $44,53( \pm 12,09)^{\mathrm{b}}$ \\
C14:0 (Mirístico) & $7,95( \pm 2,47)^{\mathrm{a}}$ & $17,61( \pm 4,13)^{\mathrm{b}}$ \\
C16:0 (Palmítico) & $27,06( \pm 6,34)^{\mathrm{a}}$ & $14,17( \pm 5,75)^{\mathrm{b}}$ \\
C16:1 (Palmitoléico) & $11,94( \pm 6,63)^{\mathrm{a}}$ & $2,85( \pm 2,04)^{\mathrm{b}}$ \\
C17:0 (Margárico) & $1,42( \pm 0,47)^{\mathrm{a}}$ & $0,38( \pm 0,09)$ \\
C18:0 (Esteárico) & $10,39( \pm 7,52)^{\mathrm{a}}$ & $3,08( \pm 1,16)^{\mathrm{b}}$ \\
C18:1 (Oléico e Isômeros)* & $5,39( \pm 2,28)^{\mathrm{a}}$ & $4,84( \pm 1,70)^{\mathrm{a}}$ \\
C18:2 (Linoléico e isômeros)**W-6 & $4,47( \pm 2,86)^{\mathrm{a}}$ & $4,27( \pm 3,07)^{\mathrm{a}}$ \\
C18:3 (Linolênico)W-3 & $2,22( \pm 0,71)^{\mathrm{a}}$ & $0,77( \pm 0,74)^{\mathrm{b}}$ \\
C20:2 (Eicosadienóico) & - & - \\
C20:4 (Araquidônico e Isômeros)***W-6 & $4,42( \pm 1,18)^{\mathrm{a}}$ & $0,64( \pm 0,54)^{\mathrm{b}}$ \\
C20:5 (EPA) W-3 & $8,67( \pm 2,47)^{\mathrm{a}}$ & $2,65( \pm 1,97)^{\mathrm{b}}$ \\
C22:5 (Docosapentaenóico) & $1,84( \pm 0,71)$ & $0,58( \pm 0,51)$ \\
C22:6 (DHA) W-3 & $10,60( \pm 4,63)^{\mathrm{a}}$ & $1,76( \pm 1,11)^{\mathrm{b}}$ \\
Totais: Saturados & 52,88 & 79,77 \\
\multicolumn{1}{c}{$\quad$ Monoinsaturados } & 17,33 & 7,69 \\
Poliinsaturados & 32,22 & 10,67 \\
Reli. Sat. hiper/ hipo**** & 0,61 & 0,13 \\
Rel. W-3/ W-6 & 0,71 & 1,73 \\
\hline
\end{tabular}

* Oléico e Vacênico; ** Linoléico e Linoléico Conjugado; *** Araquidônico e Eicosatetraenóico; **** Relação ácido graxo hipercoleristêmico/hipocoleristêmico = ácido graxo hipercoleristêmico (C14: 0 + C16:0)/ácido graxo hipocoleristêmico (monoinsaturado + poliinsaturado); Valores na mesma linha com letras diferentes apresentam diferença significativa ao nível de $1 \%$. 
TABELA III - Perfil de ácidos graxos de maçunim cru e cozido em leite de coco da cidade de Maceió-AL

\begin{tabular}{lll}
\hline Ácidos Graxos & Maçunim cru & Maçunim cozido em leite de coco e temperos \\
\hline C12:0 (Láurico) & $9,41( \pm 6,26)^{\mathrm{a}}$ & $46,46( \pm 12,96)^{\mathrm{b}}$ \\
C14:0 (Mirístico) & $5,50( \pm 2,93)^{\mathrm{a}}$ & $17,05( \pm 4,60)^{\mathrm{b}}$ \\
C16:0 (Palmítico) & $22,45( \pm 7,59)^{\mathrm{a}}$ & $12,03( \pm 2,11)^{\mathrm{b}}$ \\
C16:1 (Palmitoléico) & $6,37( \pm 2,70)^{\mathrm{a}}$ & $1,02( \pm 0,56)^{\mathrm{b}}$ \\
C17:0 (Margárico) & $1,67( \pm 0,09)$ & $0,67( \pm 0,38)$ \\
C18:0 (Esteárico) & $7,94( \pm 2,16)^{\mathrm{a}}$ & $3,20( \pm 1,01)^{\mathrm{b}}$ \\
C18:1 (Oléico e Isômeros)* & $6,84( \pm 2,13)^{\mathrm{a}}$ & $6,72( \pm 1,12)^{\mathrm{a}}$ \\
C18:2 (Linoléico e isômeros)**W-6 & $3,63( \pm 3,58)^{\mathrm{a}}$ & $4,26( \pm 4,16)^{\mathrm{b}}$ \\
C18:3 (Linolênico) W-3 & $1,13( \pm 0,85)^{\mathrm{a}}$ & $0,42( \pm 0,39)^{\mathrm{b}}$ \\
C20:2 (Eicosadienóico) & $1,39( \pm 0,05)$ & $0,76( \pm 0,43)$ \\
C20:4 (Araquidônico e Isômeros)***W-6 & $4,31( \pm 1,04)^{\mathrm{a}}$ & $0,74( \pm 0,71)^{\mathrm{b}}$ \\
C20:5 (EPA) W-3 & $6,76( \pm 1,48)^{\mathrm{a}}$ & $3,01( \pm 1,63)^{\mathrm{b}}$ \\
C22:5 (Docosapentaenóico) & $2,57( \pm 0,14)$ & $1,09( \pm 0,58)$ \\
C22:6 (DHA) W-3 & $8,80( \pm 1,50)^{\mathrm{a}}$ & $2,00( \pm 1,93)^{\mathrm{b}}$ \\
Totais: Saturados & 46,97 & 79,41 \\
$\quad$ Monoinsaturados & 13,21 & 7,74 \\
$\quad$ Poliinsaturados & 28,59 & 12,28 \\
Poli./Sat. & 0,61 & 0,15 \\
Rel. hiper/hipo***** & 0,67 & 1,45 \\
Rel. W-3/ W-6 & 2,10 & 1,09 \\
\hline
\end{tabular}

* Oléico e Vacênico; ** Linoléico e Linoléico Conjugado; *** Araquidônico e Eicosatetraenóico; **** Relação ácido graxo hipercoleristêmico / hipocoleristêmico = ácido graxo hipercoleristêmico $(\mathrm{C} 14: 0+\mathrm{C} 16: 0) / a ́ c i d o ~ g r a x o$ hipocoleristêmico (monoinsaturado + poliinsaturado); Valores na mesma linha com letras diferentes apresentam diferença significativa ao nível de $1 \%$.

TABELA IV - Perfil de ácidos graxos de Unha de velho crua e cozida em leite de coco da cidade de Maceió-AL

\begin{tabular}{lll}
\hline Ácidos Graxos & Unha de velho crua & Unha de velho cozida em leite de coco e temperos \\
\hline C12:0 (Láurico) & $4,42( \pm 2,18)^{\mathrm{a}}$ & $45,05( \pm 9,15)^{\mathrm{b}}$ \\
C14:0 (Mirístico) & $5,66( \pm 1,42)^{\mathrm{a}}$ & $18,15( \pm 2,44)^{\mathrm{b}}$ \\
C16:0 (Palmítico) & $26,75( \pm 5,88)^{\mathrm{a}}$ & $13,89( \pm 4,24)^{\mathrm{b}}$ \\
C16:1 (Palmitoléico) & $12,68( \pm 4,94)^{\mathrm{a}}$ & $2,98( \pm 2,13)^{\mathrm{b}}$ \\
C17:0 (Margárico) & $1,43( \pm 0,04)$ & $1,50( \pm 2,19)$ \\
C18:0 (Esteárico) & $8,28( \pm 2,84)^{\mathrm{a}}$ & $3,79( \pm 2,88)^{\mathrm{b}}$ \\
C18:1 (Oléico e Isômeros)* & $10,02( \pm 2,05)^{\mathrm{a}}$ & $6,56( \pm 3,37)^{\mathrm{b}}$ \\
C18:2 (Linoléico e isômeros)** W-6 & $4,64( \pm 2,27)^{\mathrm{a}}$ & $2,60( \pm 1,04)^{\mathrm{b}}$ \\
C18:3 (Linolênico) W-3 & $1,27( \pm 0,42)^{\mathrm{a}}$ & $0,42( \pm 0,49)^{\mathrm{b}}$ \\
C20:2 (Eicosadienóico) & - & - \\
C20:4 (Araquidônico e Isômeros)***W-6 & $4,55( \pm 1,54)^{\mathrm{a}}$ & $0,99( \pm 1,24)^{\mathrm{b}}$ \\
C20:5 (EPA) W-3 & $6,12( \pm 0,70)^{\mathrm{a}}$ & $1,08( \pm 0,27)^{\mathrm{b}}$ \\
C22:5 (Docosapentaenóico) & $2,55( \pm 0,18)$ & $0,46( \pm 0,14)$ \\
C22:6 (DHA) W-3 & $9,19( \pm 4,32)^{\mathrm{a}}$ & $2,01( \pm 1,73)^{\mathrm{b}}$ \\
Totais: Saturados & 46,54 & 82,38 \\
$\quad$ Monoinsaturados & 22,70 & 9,54 \\
$\quad$ Poliinsaturados & 28,32 & 7,56 \\
Poli./Sat. & 0,60 & 0,09 \\
Rel. hiper / hipo**** & 0,63 & 1,87 \\
Rel. W-3/ W-6 & 1,80 & 0,98 \\
\hline
\end{tabular}

* Oléico e Vacênico; ** Linoléico e Linoléico Conjugado; *** Araquidônico e Eicosatetraenóico; **** Relação ácido graxo hipercoleristêmico / hipocoleristêmico = ácido graxo hipercoleristêmico $(\mathrm{C} 14: 0+\mathrm{C} 16: 0) /$ ácido graxo hipocoleristêmico ( monoinsaturado + poliinsaturado);Valores na mesma linha com letras diferentes apresentam diferença significativa ao nível de $1 \%$. 
ômega-6 (7,94\%). Todos os moluscos apresentaram valores similares para a relação poliinsaturados/saturados igual a 0,6 .

Na relação entre ácido graxo hiper/hipocoleristêmico, o sururu apresentou maiores teores $(0,71)$, os outros moluscos apresentaram valores similares. Quanto à relação ômega-3/ômega-6, o sururu apresentou o valor mais elevado $(2,41)$, o menor valor foi detectado em unha de velho $(1,80)$.

Os elevados percentuais de ácido palmítico encontrado em todos os moluscos, também foram detectados por Badolato et al. (1994), em filés e polpas de peixes marinhos analisados nas diferentes estações do ano, variando de $14,2 \%$ a $31,3 \%$ nos filés e $15,5 \%$ a $29,1 \%$ em polpa. Os autores também constataram para quase todas as espécies a presença de quantidades consideráveis de ácido mirístico.

No presente estudo, o ácido linolênico apresentou em todos os moluscos, teores mais elevados que os encontrados por Romero et al. (1996), em conservas de pescados no Chile. Badolato et al. (1994) encontraram em polpas de peixes marinhos valores de linolênico variando de 0,9 a 2,5. O ácido $\alpha$-linolênico é importante na modulação do metabolismo do ácido araquidônico, com conseqüente redução de agregação plaquetária. $\mathrm{O}$ aumento na sua quantidade nas dietas é benéfico em certos estágios de determinadas doenças, pois elevam a concentração dos ácidos eicosapentaenóico-EPA e docosaexaenóico-DHA, sendo este último indispensável ao funcionamento cerebral (Simopoulos, 1989, Apud Saldanha et al., 2001).

Na espécie unha de velho destaca-se o percentual do ácido monoinsaturado oléico, da família ômega-9, que tem sido apontado como hipolipidêmico, reduzindo o colesterol e a lipoproteína de baixa densidade ( LDL), responsáveis pela formação de ateromas (McNamara, 1990, Apud Monteiro, 1998; Spector, 1999, Apud Saldanha et al., 2001).

Após o cozimento, observaram-se alterações no perfil dos ácidos graxos de todos os moluscos pela interação lipídica com o leite de coco. Os teores dos saturados láurico e mirístico aumentaram significativamente em relação aos valores in natura em todas as espécies. Estes ácidos graxos são encontrados em elevadas proporções no leite de coco, 58,48\% e 15,06\% (Silva, 1971 ) e $46,5 \%$ e $17,9 \%$ (ITAL, 1980 ) e promovem hipercolesterolemia (Lima et al., 2000). Por outro lado, o ácido esteárico apresentou redução significativa em relação aos valores in natura em todas as espécies estudadas.

Verificou-se redução significativa nos percentuais do ácido monoinsaturado oléico apenas em unha de velho. $\mathrm{O}$ ácido linoléico sofreu redução significativa em unha de velho e maçunim. Os poliinsaturados linolênico, araquidônico, EPA e DHA apresentaram redução significativa em todas as espécies, em decorrência da diluição destes em relação aos componentes lipídicos do coco.

As relações poliinsaturados/saturados, hipercoleristêmicos/hipocoleristêmicos e ômega-3 e ômega-6 foram alteradas em todas as espécies prejudicando-os nutricionalmente.

Estes resultados demonstram a influência do cozimento destes moluscos utilizando o leite de coco, cujos ácidos saturados predominantes foram absorvidos durante a cocção. Desta forma, para se poder usufruir os efeitos benéficos relativos à ingestão dos ácidos graxos monoe poliinsaturados presentes nestes moluscos seria conveniente a adoção de novas formas culinárias de preparo destes alimentos. Os resultados obtidos podem servir de subsídio para possibilitar compilação de dados para posterior inclusão em tabelas de composição química de alimentos regionais/nacionais, possibilitando fornecer aos profissionais da área de saúde informações necessárias sobre estes constituintes, permitindo, assim, orientação dietética adequada.

\section{CONCLUSÕES}

Tendo como base os resultados obtidos, e nas condições em que o trabalho foi realizado, pode-se concluir que: - Os moluscos crus apresentaram elevados teores de proteínas, lipídeos, cinzas e calorias; também podem ser considerados fontes alimentares de ácidos graxos poliinsaturados, de EPA, DHA e araquidônico.

- Observou-se, em base seca, que a cocção provocou alteração significativa na composição química destes alimentos, em relação a: redução no teor de umidade, proteínas e elevação nos teores de lipídeos e cinzas.

- Após o cozimento na presença de leite de coco, os teores dos ácidos saturados láurico e mirístico aumentaram significativamente em relação aos valores in natura, enquanto o ácido esteárico apresentou redução significativa em todos os moluscos.

- Verificou-se após cocção, redução significativa nos percentuais dos ácidos poliinsaturados linolênico, araquidônico, EPA e DHA em todas as espécies.

- Seria conveniente a adoção de novas formas culinárias de preparo destes alimentos, para evitar reprodução de ácidos graxos saturados indesejáveis sob o ponto de vista nutricional.

\section{AGRADECIMENTOS}

À Fundação de Amparo à Pesquisa do Estado de Alagoas (FAPEAL), pelo auxílio financeiro e pela Bolsa de Iniciação Científica concedida à aluna; ao PIBIC/ 
CNPq/UFAL, pela Bolsa de Iniciação Científica concedida à aluna; aos Professores Jairo Calado e Fernando Mendonça, pela realização das análises estatísticas.

\section{ABSTRACT}

Fatty acids composition, chemical centesimal composition and caloric value in raw and boiled mollusks with milk coconut in the city of Maceió, Alagoas, Brazil

The aim of this study was to assess the profile of fatty acids, the chemical centesimal composition and caloric value of raw and boiled mollusks in the city of Maceió. Three species were analyzed: Mytella falcata, Anomalocardia brasiliana and Tagelus plebeus, known locally as sururu, maçunim and unha de velho, respectively. Raw and boiled (with coconut milk) specimens were evaluated. Uncooked mollusks were moist and rich in proteins. The greatest concentration of lipids and ashes was found in sururu and maçunim, respectively. Sururu had the highest caloric value. Dry coction resulted in a significant reduction in the amount of protein and in a marked increase in the levels of lipids and ashes in mollusks. The highest caloric value was seen in boiled Tagelus plebeus. The predominant polyunsaturated fatty acids in all the raw samples were docosahexaenoic and eicosapentaenoic. Linoleic, linolenic, and aArachidonic acids were also detected. After boiling, the levels of the saturated lauric and miristic acids rose significantly, whereas those of stearic acid decreased considerably in all the raw samples. Linoleic acid was notably reduced in unha de velho and maçunim. The polyunsaturated linolenic, arachidonic, eicosapentaenoic, and docosahexaenoic acids were markedly reduced in all mollusks.

UNITERMS: Fatty acids omega-3. Fatty acids omega6. Centesimal composition. Mollusks cooked with coconut milk.

\section{REFERÊNCIAS BIBLIOGRÁFICAS}

ASBURY, C.E. Salinity of Mundaú Lagoon, Brazil, 19721978, in relation to disapperance of sururu, Mytella falcata. Bol. Núcleo Est. Ciênc. Mar., Maceió, v.1, p. 17-26.

ASSOCIATION OF OFFICIAL ANALYTICAL CHEMISTS, Washington, D. C. Official methods of analysis. 15 ed., Washington, 1990. 109p.
BELDA, M. C. R.; POURCHET-CAMPOS, M. A. Ácidos graxos essenciais em nutrição: uma visão atualizada. Ciênc. Tecnol. Aliment., Campinas, v. 11,n.1,p.5-35, 1991.

BADOLATO, E. S. G.; CARVALHO, J. B.; MELLO, M. R. P.; TAVARES, M.; CAMPOS, N. C.; AUEDPIMENTEL, S.; MORAIS, C. Composição centesimal de ácidos graxos e valor calórico de cinco espécies de peixes marinhos nas diferentes estações do ano. Rev. Inst. Adolfo Lutz, São Paulo, v. 54, n.1, p. 27-35, 1994.

BRAGAGNOLO N.; RODRIGUEZ-AMAYA D. Otimização da determinação de colesterol por CLAE e teores de colesterol, lipídeos totais e ácidos graxos em camarão rosa (Penaeus brasilienses). Ciênc. Tecnol. Aliment., Campinas, v. 17, n. 3, p.275-280, 1997.

BRITISH NUTRITION FOUNDATIONS. Unsaturated fatty acids: nutritional and physiological significance; the report of the British Nutrition Foundation's Task Force. London: Chapman \& Hall, 1994. 211p.

CALADO, T.C.S.; SOUSA, E.C. Crustáceos do Complexo Estuarino-Lagunar Mundaú/Manguaba-Alagoas. Maceió:FAPEAL, 2002. 116p.

FOLCH, J.; LEES, M.; SLOANNE STANLEY, G. H. A simple method for the isolation and purification of total lipide from animal tissues. J. Biol. Chem., Baltimore, v. 226, p. 497-509, 1957.

HARTMAN, L.; LAGO, B. C. A. Rapid preparation of fatty methyl esters from lipids. Lab. Pract., v. 22, p. 475-477, 1973.

INSTITUTO DE TECNOLOGIA DE ALIMENTOS. Série frutas tropicais-5-coco. Campinas, 1980. 285p.

LAJOLO, F. M. Grupo de trabalho: Composição de Alimentos. Bol. SBCTA, v. 29, n.1, p. 57-69., 1995.

LIMA, F.E.L.; MENEZES, T.N.; TAVARES, M.P.; SZARFARC, S.C.; FISBERG, R.M. Ácidos graxos e doenças cardiovasculares: uma revisão. Rev. Nutr., Campinas, v.13, n.2, p. 73-80, 2000.

LIMA, M.M.R.; MOREIRA, N.X.; SANTOS, B.M.A.; MANCINI FILHO, J.; FERNANDES, L.C. Ácidos graxos e câncer. In: CURI, R.; POMPÉIA, C.; MIYASAKA, C.K.; PROCÓPIO, J. Entendendo a gordura - os ácidos graxos. São Paulo: Manole, 2002; p. 525-536. 
MASSON, L. S.; MELLA, M. A.R.; CAGALJ, A. K.; ROMERO, N. P. Contenido de colesterol y otros esteroles em alimentos chilenos. Rev. Chil. Nutr., v. 18, n.3, 1990.

MONTEIRO, E.M. Influência do cruzamento Ile de France $x$ Corriedale (F1) nos parâmetros de qualidade da carne de cordeiro. São Paulo, 1998. 99p. [Tese de Doutorado - Faculdade de Ciências Farmacêuticas - USP].

MOURA, A. F. P.; TENUTA FILHO, A.Efeito do processamento sobre os níveis de colesterol e 7cetocolesterol em camarão-rosa. Ciên. Tecnol. Aliment., Campinas, v. 22, n. 2, p.117-121, 2002.

PEDROSA, L.F.C.; COZZOLINO, S.M.F. Composição centesimal e de minerais de mariscos crus e cozidos da cidade de Natal/RN. Ciênc. Tecnol. Aliment. v.21, n.2, p.154-157, 2001.

PRICE, J.F.; SCHWEIGERT, B.S. Ciencia de la carne y de los productos carnicos. 2 ed. Zaragoza: Editorial Acribia, 1994. 581p.

POMPÉIA, C.; PROCÓPIO, J.; CURI, R. Fatty acids and the immune system. Rev. Bras. Ciênc. Farm. v. 35, n.2, p. 165-194., 1999.
ROMERO, N.P.; ROBERT, P.C.; MASSON, L.S.; LUCK, C.U.; BUSCHMANN, A. Composición en ácidos grasos y aporte de colesterol de conservas de jurel, sardina, salmón y atún al natural. Arch. Latinoam. Nutr., v.46, p.75-77, 1996.

SALDANHA, T.; GASPAR, A.; SANTANA, D.M.N.S. Composição Centesimal da carne de Escargot criado em Iguape-SP. Rev. Hig. Alim. v.15, n.85, p. 69-74, 2001.

SILVA, A.A.M. Estudo da estabilidade do leite de coco concentrado. Campinas, 1971. 53p. [Tese de Mestrado. Faculdade de Tecnologia de Alimentos. Universidade Estadual de Campinas].

SILVA, C. S., PEREIRA-BARROS, J. B. Inventário da malacofauna do complexo lagunar Mundaú-Manguaba, Alagoas. Bol. Estud. Ciênc. Mar., n. 6, p. 65-74. 1987.

TURATTI, J.M.; GOMES, R.A.R.; ATHIÉ, I. LIPIDDEOS: Aspectos funcionais e novas tendências. Campinas: ITAL, 2002. 78p.

Recebido para publicação em 09 de fevereiro de 2004. Aceito para publicação em 08 de outubro de 2004. 